\title{
A INTERVENÇÃO PROFISSIONAL JUNTO DE VÍTIMAS DE VIOLÊNCIA DOMÉSTICA LGBT
}

\author{
INTERVENCIÓN PROFESIONAL CON \\ VÍCTIMAS DE VIOLENCIA DOMÉSTICA LGBT \\ PROFESSIONAL INTERVENTION WITH \\ VICTIMS OF LGBT DOMESTIC VIOLENCE
}

Ana Sofia Neves ${ }^{1}$

${ }^{1}$ Instituto Universitário da Maia, Maia, Portugal

\section{Resenha de}

Moleiro, C., Pinto, N., O. J., \& Santos, H. (2016). Violência Doméstica: boas práticas no apoio a vítimas LGBT. Lisboa: Comissão para a Cidadania e Igualdade de Género.

Tal como tem vindo a acontecer no resto da Europa, de um modo geral, Portugal tem preconizado, nas últimas décadas, passos fundamentais no que à questão da consagração dos direitos das pessoas lésbicas, gays, bissexuais e trans (LGBT) diz respeito. Destaca-se, em 2010, a promulgação da lei que permite o casamento entre pessoas do mesmo sexo (Lei $n^{\circ}$ 9/2010 de 31 de maio), em 2011, a alteração da lei de identidade de género (Lei no 7/2011 de 15 de março), em 2016 a aprovação da lei da adoção por casais do mesmo sexo (Lei n 2/2016 de 29 de fevereiro) e, no mesmo ano, a alteração da lei que garante o acesso de todas as mulheres à procriação medicamente assistida (Lei n 17/2016 de 20 de junho). Para além da efetivação de direitos formais, o país tem vindo a investir na criação de serviços e estruturas de apoio a vítimas LGBT e na formação de agentes de intervenção especializados/as, reconhecendo o risco a que estas pessoas estão frequentemente expostas.

O livro Violência Doméstica: boas práticas no apoio a vítimas LGBT, da autoria de Carla Moleiro, Nuno Pinto, João Manuel Oliveira e Maria Helena Santos e editado pela Comissão para a Cidadania e Igualdade de Género (CIG), trata-se do primeiro guia publicado em Portugal sobre violência doméstica, dirigido a profissionais de estruturas de apoio a vítimas, que sistematiza as boas práticas no que se refere à intervenção com as pessoas LGBT. Nessa medida, vem preencher um vazio previamente existente no sistema de referenciação e de apoio a vítimas de violência doméstica que, sendo genérico e heteronormativo, não acautelava, pelo menos de uma forma estruturada e empiricamente validada, as especificidades das vítimas LGBT. São estas especificidades que justificam que a intervenção seja, também ela, específica. O livro faz desta questão a sua questão central.

As pessoas LGBT vítimas de violência doméstica são, não raras vezes, sujeitas a outros focos de vitimação, pelo facto de serem lésbicas, gays, bissexuais e trans (Fundamental Rights of the European Union - FRA, 2014; Nogueira \& Oliveira, 2010). Este adensamento de vulnerabilidades torna a intervenção dos e das profissionais altamente complexa, exigindo a sua formação especializada e constante atualização.

Recorde-se, a título ilustrativo, e de acordo com a Organização Mundial de Saúde e outros organismos (WHO et al., 2015), que as pessoas LGBT são mais discriminadas 
e vítimas de exclusão do que as pessoas heterossexuais e cissexuais em todos os contextos, sobrepondo-se à discriminação e à exclusão baseada na orientação sexual e/ou na identidade de género, a discriminação e a exclusão com base no sexo, na etnia, na idade, na religião, na pobreza, na migração, na diversidade funcional e na condição de saúde. As pessoas LGBT estão, por exemplo, em maior risco de desenvolver sintomatologia depressiva e ansiógena, de cometer suicídio, de ficar em situação de sem-abrigo e de viver em precariedade.

A discriminação e a violência contribuem não apenas para a marginalização das pessoas LGBT, mas igualmente para a sua maior vulnerabilidade à doença, acentuando o mal-estar e o sofrimento (Herek, Chopp, \& Strohl, 2007). O isolamento social, fruto da ausência de suporte, da não-aceitação, da vergonha e do medo, entre outros fatores, fazem com que as pessoas sobrevivam à margem e em silêncio. As atitudes de patologização por parte dos e das profissionais (Moita, 2006) são, muitas vezes, impeditivas do apoio efetivo, sendo o sistema percebido pelas pessoas LGBT como uma ameaça e não como uma oportunidade. Às pessoas trans é frequentemente negado o seu direito à auto-determinação, ficando sujeitas a um diagnóstico clínico que, ao mesmo tempo que as parece legitimar, lhes reforça o estigma (Pinto \& Moleiro, 2012).

Com efeito, as vítimas LGBT enfrentam múltiplos desafios não apenas no que respeita à sua orientação sexual ou à sua identidade de género, às experiências pessoais de vitimação no contexto da intimidade ou noutros, mas igualmente no que se refere aos processos de revelação, de denúncia e de contacto/articulação com o sistema de apoio, quer no âmbito da saúde, da justiça ou da área social (Goldberg, 2016), só para citar alguns exemplos. A expressão "duplo armário” (Carneiro, 2012; Nunen, 2004) é usada, assim, para dar conta das dificuldades adicionais que estas pessoas enfrentam quando à visibilidade da sua orientação sexual não normativa se soma a da visibilidade da vitimação que sofrem, igualmente não normativa. A estes dois armários acresce um terceiro, o sistema de apoio em si mesmo. Não estando preparado para responder às necessidades das pessoas, o sistema reforça o estigma, o preconceito e a discriminação e convida as pessoas LGBT a regressar aos armários dos quais tão difícil foi sair antes.

Se é verdade que o sexismo cria as condições para que os homens heterossexuais abusem das suas parceiras, não é menos verdade que a homofobia cria as condições para que lésbicas e gays maltratem as suas companheiras e os seus companheiros respetivamente. É preciso que quem lida com histórias de violência consiga analisar e compreender que mecanismos de opressão alimentam estes dispositivos de controlo e de poder, para agir sobre eles. É necessário também que os e as profissionais que lidam com as vítimas entendam como se constroem as vulnerabilidades das vítimas LGBT, atuando no sentido da sua superação.

O livro presta este esclarecimento e fá-lo numa linguagem simples, acessível e inclusiva, que nunca deixa de ser rigorosa. Não sendo um trabalho académico, até porque não é esse o seu objetivo, é desenvolvido por académicos e académicas, o que lhe confere precisão nos conteúdos. Tem uma matriz de orientação para a ação, mas cumpre, e bem, em simultâneo uma função pedagógica, estimuladora de uma postura crítica e transformadora.

A obra começa por apresentar a situação das pessoas LGBT em Portugal, enquadrando-a do ponto de vista legal. Clarifica de seguida conceitos chave, salientando a importância de os distinguir, e especifica a discriminação realizada em função da orientação sexual e/ou da identidade de género. Esta assenta na tríade dos i's, o insulto, a invisibilidade e o isolamento, fatores que geralmente co-existem na vida das pessoas LGBT e que põem em causa a sua saúde psicológica, física e social. 
É ainda abordada, na obra, a lei da violência doméstica e os direitos e a cidadania das pessoas LGBT, confrontando-se as similitudes e os contrastes entre a violência doméstica praticada por pessoas do mesmo sexo e de sexo diferente, pontuando a diversidade das populações LGBT. Este é outro esclarecimento importante que o livro presta, isto é, desmonta a ilusão de homogeneidade que habitualmente é associada às populações LGBT, como se constituíssem uma categoria única.

A obra apresenta ainda um conjunto de princípios reguladores da intervenção, bem como alguns desafios para a própria intervenção, tendo por referência diretrizes nacionais e internacionais. Para além dos aspetos anteriormente elencados, de notar que o livro foi escrito tendo por base entrevistas a vítimas de violência doméstica, bem como a representantes de várias Associações que intervêm em questões LGBT, violência doméstica ou igualdade de género, a saber: Associação Democrática de Defesa dos Interesses e da Igualdade das Mulheres (ADDIM); Associação de Mães e Pais pela Liberdade de Orientação Sexual e de Identidade de Género (AMPLOS); Associação Portuguesa de Apoio à Vítima (APAV); Casa Qui - Associação de Solidariedade Social; Associação ILGA Portugal - Intervenção Lésbica, Gay, Bissexual e Transgénero; Opus Gay; Rede ex aequo - Associação de jovens lésbicas, gays, bissexuais, trans, intersexo e apoiantes; e União de Mulheres Alternativa e Resposta (UMAR). É este um dos seus pontos mais fortes.

$\mathrm{Na}$ realidade, a auscultação das próprias vítimas e das associações e organizações que com elas trabalham é essencial. Este cruzamento de conhecimentos, experiências e perspetivas confere a este guia um caráter integrador, agregando as vozes dos diferentes intervenientes. Servirá por isso, este guia, muitos fins. Será um instrumento de trabalho a ser usado nas estruturas de apoio às vítimas e nas associações LGBT pelos técnicos e pelas técnicas, mas também um documento de consulta para quem está a formar-se ou faz investigação e intervenção na área.

\section{Referências}

Carneiro, N. S. (2012). Violências íntimas multimarginalizadas: pensar e agir contra a normatividade. In S. Neves (Org.), Intervenção psicológica e social com vítimas. Volume II. Adultos (pp. 167-192). Coimbra, PORT: Edições Almedina

FRA. (2014). EU LGBT survey European Union lesbian, gay, bisexual and transgender survey. Austria: FRA.

Goldberg, A. (2016). The Sage Encyclopedia of LGBTQ Studies. Thousand Oaks: Sage.

Herek, G., Chopp, R., \& Strohl, D. (2007). Sexual Stigma: Putting Sexual Minority Health Issues in Context. In H. Meyer \& M. E. Northridge (Orgs.), The Health of Sexual Minorities Public Health Perspectives on Lesbian, Gay, Bisexual and Transgender Populations (pp. 171-208). New York: Springer

Moita, G. (2006). A patologização da diversidade sexual. Revista Crítica de Ciências Sociais, $76,53-72$.

Moleiro, C., Pinto, N., O. J., \& Santos, H. (2016). Violência Doméstica: Boas práticas no apoio a vítimas LGBT. Lisboa: Comissão para a Cidadania e Igualdade de Género. 
Nogueira, C. \& Oliveira, J. M. (2010). Estudo sobre a discriminação em função da orientação sexual e da identidade de género. Lisboa: CIG. Recuperado de http://www.igualdade.gov.pt/images/stories/documentos/documentacao/publicacoes/Estudo OrientacaoSexual IdentidadeGenero.pdf

Nunen, A. (2004). Violência doméstica entre casais homossexuais: o segundo armário? PSICO, 35(1), 1-21.

Pinto, N. \& Moleiro, C. (2012). As experiências dos cuidados de saúde de pessoas transexuais em Portugal: perspetivas de profissionais de saúde e utentes. Psicologia, 26(1), 129-151.

WHO et al. (2015). Ending violence and discrimination against lesbian, gay, bisexual, transgender and intersex people. Geneva: Author.

\author{
ANA SOFIA NEVES \\ https://orcid.org/0000-0001-6180-4932 \\ Doutora em Psicologia Social pela Universidade do Minho (Portugal). \\ É Professora Assistente do Instituto Universitário da Maia (ISMAI, Portugal) \\ e membro do Centro Interdisciplinar de Estudos de Gênero (CIEG- Instituto \\ de Ciências Sociais e Políticas da Universidade de Lisboa). \\ Endereço: Av. Carlos de Oliveira Campos, 4475-690 Maia, Portugal. \\ E-mail: $\underline{\text { asneves@docentes.ismai.pt }}$
}

\begin{tabular}{l|l} 
Histórico & $\begin{array}{l}\text { Submissão: 25/08/2017 } \\
\text { Aceite: 16/09/2019 }\end{array}$ \\
\hline
\end{tabular}

